San Jose State University

SJSU ScholarWorks

Master's Theses

Master's Theses and Graduate Research

1994

\title{
The development of a movement style incorporating Western modern and traditional Chinese classical dance
}

\author{
Bih-Tau Sung \\ San Jose State University
}

Follow this and additional works at: https://scholarworks.sjsu.edu/etd_theses

\section{Recommended Citation}

Sung, Bih-Tau, "The development of a movement style incorporating Western modern and traditional Chinese classical dance" (1994). Master's Theses. 874.

DOI: https://doi.org/10.31979/etd.tzxv-ztd5

https://scholarworks.sjsu.edu/etd_theses/874

This Thesis is brought to you for free and open access by the Master's Theses and Graduate Research at SJSU ScholarWorks. It has been accepted for inclusion in Master's Theses by an authorized administrator of SJSU ScholarWorks. For more information, please contact scholarworks@sjsu.edu. 


\section{INFORMATION TO USERS}

This manuscript has been reproduced from the microfilm master. UMI fitions the text directly from the original or copy submitted. Thus, some thesis and dissertation copies are in typewriter face, while others may be from any type of computer printer.

The quality of this reproduction is dependent upon the quality of the copy submitted. Broken or indistinct print, colored or poor quality illustrations and photographs, print bleedthrough, substandard margins, and improper alignment can adversely affect reproduction.

In the unlikely event that the author did not send UMI a complete manuscript and there are missing pages, these will be noted. Also, if unauthorized copyright material had to be removed, a note will indicate the deletion.

Oversize materials (e.g., maps, drawings, charts) are reproduced by sectioning the original, beginning at the upper left-hand corner and continuing from left to right in equal sections with small overlaps. Each original is also photographed in one exposure and is included in reduced form at the back of the book.

Photographs included in the original manuscript have been reproduced xerographically in this copy. Higher quality $6^{\prime \prime} \times 9^{\prime \prime}$ black and white photographic prints are available for any photographs or illustrations appearing in this copy for an additional charge. Contact UMI directly to order.

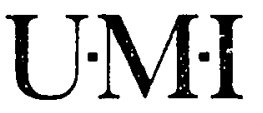

University Microfilms International

A Bell \& Howell Information Company

300 North Zeeb Road. Ann Arbor. MI 48106-1346 USA

$313 / 761-4700 \quad 800,521-0600$ 


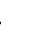


Order Number 1959057

The development of a movement style incorporating Western modern and traditiona Chinese classical dance

Sung, Bih-Tau, M.A.

San Jose State University, 1994 

THE DEVELOPMENT OF A MOVEMENT STYLE INCORPORATING WESTERN MODERN AND TRADITIONAL CHINESE CLASSICAL DANCE

\author{
A Thesis \\ Presented to \\ The Faculty of the Department of Theatre Arts \\ San Jose State University
}

In Partial Fulfillment

of the Requirements for the Degree

Master of Arts

by

Bih-Tau Sung

August, 1994 
๑ 1994

Bih-Tau Sung

ALL RIGHTS RESERVED 
APPROVED FOR THE DEPARTMENT OF THEATRE ARTS
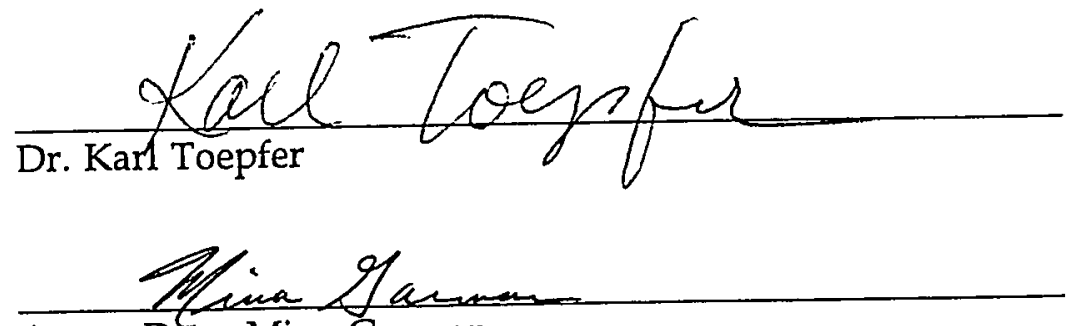

Assoc. Dean Mina Garman

$\longrightarrow$ anet $\operatorname{Van}$ Sural Prof. Janet-Van Swoll

APPROVED FOR THE UNIVERSITY

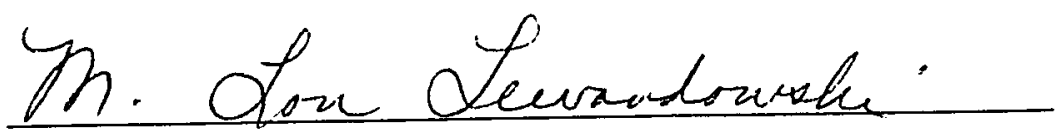




\begin{abstract}
THE DEVELOPMENT OF A MOVEMENT STYLE INCORPORATING WESTERN MODERN AND TRADITIONAL CHINESE CLASSICAL DANCE
\end{abstract}

by Bih-Tau Sung

This project was an attempt to merge and perform apparently contradictory dance styles--classical Chinese dance and Western modern dance. The solution was to create dances in which a Western sense of movement embodied Chinese philosophical values, resulting in a new movement style. Five dances were choreographed. The first, Enlightenment, was a solo dance blending modern dance and Chinese dance. The second, Nostalgia, was a duet that was very modern in interpretation. The third dance, Enchanting Celestial, was drawn from Chinese classical dance. The fourth dance, Horizon, was modern dance and music. Dream of the Red Chamber was the final dance and was a blending of the two styles. The most obvious elements seen from the two different styles were: movement formations, stilted versus flowing designs, focus and performance techniques, and movement selection. In addition, the formations obviously served as the main distinction between the two styles in the dance. Various choreographic devices were used to help effect and enhance the objective of blending the styles of Chinese and modern dance. In summary, the choreographer felt that since modern dance incorporates various styles of movement, it was difficult at times for the audience to differentiate between the two movement styles or to perceive the movement as a new movement style. 


\section{TABLE OF CONTENTS}

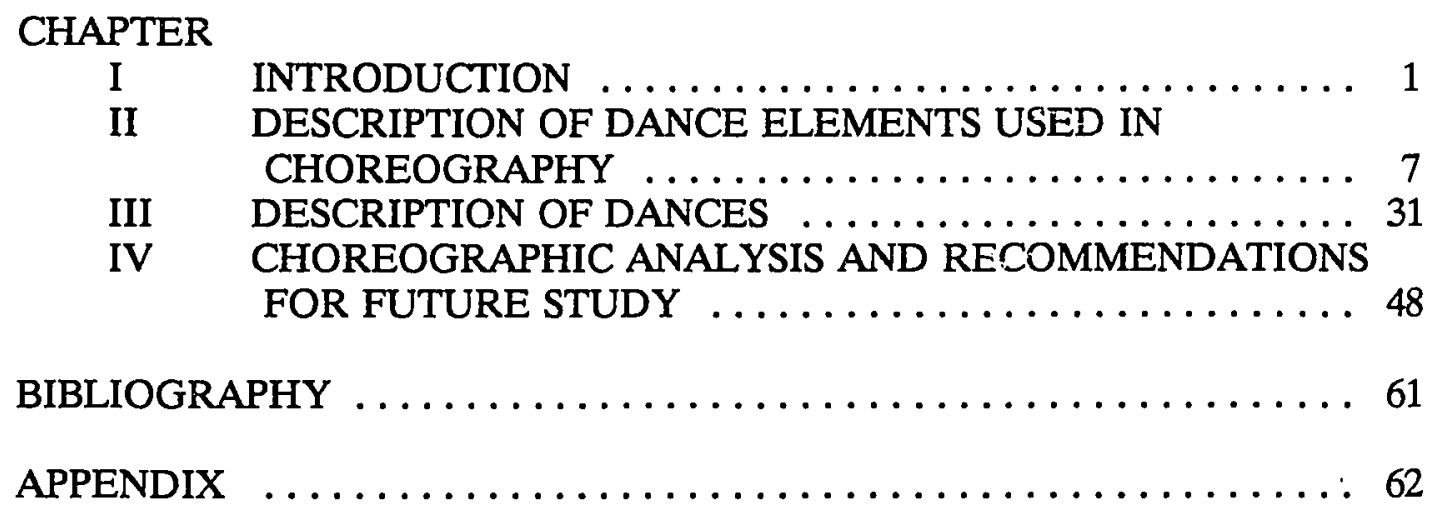


CHAPTER I

\section{INTRODUCTION}

This creative project, a modern dance concert, was choreographed by Bih-Tau Sung and performed in December, 1992. It was the intent of the choreographer to explore the styles of classical Chinese dance and Western modern dance within the context of five choreographic works.

\section{PURPOSE OF THE PROJECT}

The purpose of the project was to show traditional forms of classical Chinese dance and Western modern dance. Modern dance represents American free thinking, allowing the dancer to use a wide range of movement. This is totally opposite to the classical forms of Chinese dance, which has limitations in their movements. it was the intent of this project to explore both styles of movement and to choreograph dance works in the attempt to use the influence of another culture and infuse that culture's movement with Western modern dance.

The project was selected because of the choreographer's interest and training in Chinese opera technique, ballet, and modern dance. Coming from Taiwan, the choreographer experienced a different attitude in regard to viewing dance in the United States. This perhaps may be attributed to different cultural attitudes and 
perceptions. Such attitudes and perceptions might be received differently from culture to culture, in particular in cultures where specific ideas have direct symbolic interpretation. For example, the concept of unity found in Chinese dance is a reflection of the living style in China where the emphasis of group, or community and interaction is most important. Other customs reflected in Chinese dance can be found in the use of colors such as red which stands for good luck, and black, which represents an inferior or low class. In Chinese dance, such use of color automatically determines the dance's meaning. Other Chinese customs also dictate the use of movement and props. Such ideas concerning the use of symbols became a part of the exploration in the project.

\section{THEMATIC IDEA}

\section{Enlightenment-solo}

This dance represented the ideal of movement in traditional Chinese dance. The dance portrayed an abstraction of this ideal. The dancer/choreographer presented the image of a Chinese dancer as a symbol of Chinese culture as it related to Buddhism, one of China's religions. Buddhism in China reveals the ideal state in which the individual self is united with the supreme spirit. This dance was about the state of harmony and bliss that is essential in Buddhism. 


\section{Nostalgia-duet}

In this dance it was the choreographer's intention to show the influence of Western culture. Therefore, the style of modern dance was chosen to interpret the Western values that have influenced Taiwanese women. In this dance a young woman recalled her childhood in Taiwan and realized that her experience as a child in Taiwan is different from her experience as a woman in America. Today, Chinese women are freer than they were in the early Republican years and are now allowed to work in the outside world. This new independence in these new environments has given women more respect for themselves.

\section{Enchanting Celestial-group}

This was a traditional Chinese group dance symbolizing an idealized Buddhist heaveñ. This type of dance was brought into China in the Northern Wei Dynasty, 534-550 A.D. They are called "Celestial" because originally they were danced with wings. People gradually took away these wings and added clothes. This dance sings the praise of Buddha. The image of "Saravati"--a Gnostic Being--was used to develop this dance. The image is popular in Chinese art and can be seen in such places as the caves of Tunhwang, a treasure house of Buddhist scripture and paintings.

\section{Horizon-trio}

The characters in this dance reflected the desire for freedom (a breaking away 
from Chinese tradition). Before, in the early Republican years, society treated women as inferior to the male. They were taught that humility was the nature of women. The intention of this dance was to maintain the Chinese sense of infinite space and distance, similar to the special style of Chinese painting. The dance also expressed women's tolerance of Chinese virtues and their attempts to modify those beliefs.

\section{Dream of the Red Chamber-group}

This group piece was an abstract interpretation of the well-known Chinese novel, Dream of the Red Chamber. In contrast to Horizon, this tragic story showed the traditional values of Chinese culture. The story was circulated in manuscript during the author's (Tsao Hsueh-Chin) lifetime in the eighteenth century and was published about 1910. "This two-century-old romance of Pao-Yu and his lovely Black Jade is generally regarded as the greatest of all Chinese novels. Known in Chinese as the Hung Lou Meng, it has had a history of almost as many vicissitudes as the lives of the two lovers," (Dream of the Red Chamber, Jacket Note).

The dance centered around the three characters, Black Jade, Precious Virtue, and Pao-Yu. It showed their relationships and conflicts.

\section{CHOREOGRAPHER'S APPROACH}

The choreographer used traditional Chinese dance, modern dance, and a combination of traditional Chinese and modern styles. The choreographer explored 
various elements of dance in an effort to blend the two dance styles.

Some major differences were discovered as the choreographer approached the various dances. Performing technique, which refers to how dances are performed, is approached differently in the two styles of dance. In addition, the use of focus, quality of movement and dance formations are approached differently by each style. The dances were developed and performed in order to first establish and contrast the Chinese style and modern dance. Gradually these two styles were blended in the last dance.

Enlightenment. This solo was choreographed with the intention of highlighting Chinese philosophies of Buddhism. This dance used a Chinese theme, music and props with primary modern dance movements. In this dance, there was a strong sense of Chinese religious themes, where concept of birth, aging, illness, and death enlighten people in their lives. The use of gold and red colors in the props are Chinese customs. Gold symbolizes high social status and red symbolizes joy.

Nostalgia, a duet, was choreographed from the inspiration of a 1960's Taiwanese folk song. The purpose of the dance was to depict feelings of cultural nostalgia about Taiwan. This dance used a Chinese theme, music, focus and performance technique with primarily modern dance movement.

Enchanting Celestial, was choreographed with the intent to demonstrate Chinese dance technique and style to the audience. This dance was a traditional group Chinese dance. The designs in space were even and balanced, as in traditional 
Chinese dance. Body designs were prevalently used in circular formations. Walking in the bent knees with tie feet, a rule in Chinese dance, was also used. The costumes were bright and colorful. Focus was specific, sometimes projecting directly to the audience.

Horizon was choreographed to express Chinese ideas through modern dance technique. This piece was a modern dance using Chinese concepts and designs. Theme movement was chosen to show conflict and difference in thinking between traditional and modern people. Various images and group formations were shown by the design of the dancers' bodies. Images reflected the concept of freedom and toleration in breaking traditional rules, a style best described by modern dance.

Dream of the Red Chamber was choreographed to explore both Chinese and modern dance styles. The story, costumes, headdresses, movement, and formations blended with the abstraction of the traditional style. The differences between the traditional and modern ideas were reflected within various sections of the dance. This exploration brought new, exciting and interesting results. 


\section{CHAPTER II}

\section{DESCRIPTION OF DANCE ELEMENTS USED IN CHOREOGRAPHY}

Various dance elements are used in creating and forming a dance piece. The elements described below were selected for the purpose of evaluating this creative project. The aim of this project was to show how specific elements of classical Chinese dance can be blended with American modern dance to create one form. In an attempt to accomplish this goal, it was necessary to first understand how each dance art form uses the following elements. Each element described below notes similarities and differences for each of the two dance styles. By understanding how each type of dance approaches and uses the elements, one would then be able to select movements and forms for the purpose of creating a new form.

\section{MOVEMENT}

Movements in Chinese dance have very specific interpretations. Small, curved movement and softness suggest the quality of femininity for female roles. Large, straight lines, and strong movement represent the masculinity of the male character. Movement in modern dance does not designate specific vocabulary and quality by gender. Modern movement is generic to the movement idea. The movement can be small, curved, and soft for the male character, and large, straight, and strong for the female character, depending on the intention of the choreographer. 
Body

Chinese dance utilizes shifting and rotation of the torso (spiral turning). As the dancer sits on the floor, the torso spirals with head and chest focusing toward the ceiling. This is called "Wo Yu" (卧魚). In "Shuan Yao" (澉屡), the torso swings in a circle from side, front, side, back. Turning the torso like a pinwheel is called "Yao Tzu "Fari Shen" ( as one unit in the direction of the movement.

As opposed to Chinese dance, the torso in modern dance is kept flexible allowing the movement in a great variety of ways.

Head

The placement of the head is essential in Chinese dance. The head especially emphasizes feminine elegance, as seen in a slow walking movement. It also helps to project masculine power as in, "Liang Hsiang" (相). This pose is common in the Peking Opera. The head moves on a vertical line and tilts when the torso shifts. The face is always forward or focused away from the subject, except when following a specific arm gesture. Further, the focus always follows the conveyer of the story being told, and looks forward upon finishing a series of movements.

In modern dance, the use of the head does not have specific codes or rules. 


\section{Hand}

In Chinese dance, arms, elbows, palms, wrists, and fingers (which are considered parts of the hand) are all incorporated into one movement or gesture. In traditional Chinese dance, hand movements are divided into three parts: fingers, wrists, and arms. Fingers ( 指), have two different gestures. First, the "Orchid

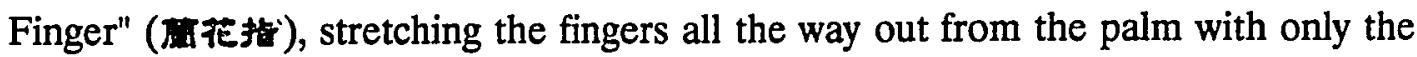
tip of the thumb placed on the top of the third section of the third finger, also called "Lotus Finger" (峦花怙). Secondly, in the "Butterfly Finger" ( circles back to meet the tip of the thumb joining together and becoming a circle. The second finger must stretch out intensely, with the rest of the fingers gradually bending in natural form. Fists suggest strength or fighting movements. For the female, the fists are grasped firmly with only thumb, second and third finger, the remaining stay in a natural form. Wrists ( have two movement positions; one turns outward, the other one turns inward. With arms ( ) the figure eight is a common technique using hand gestures in Chinese dance: in the "Cloud Hand" ( over to the center front of torso, both arms reverse in a complete circle to the right side, then the left arm opens to the left side. The end of the "Cloud Hand" movement becomes ballet's second position. In Chinese, the term for the arms in second position is called "Shan Pang" ( $w$ ). The only differences between the second position arms in the two styles are the placement of the palms, and the relationship of the hand to the lower arm. In Chinese dance, the wrist is at a right angle to the 
lower arm, with the thumb side of the hand towards the floor and the palm facing away from the body. In Western dance, the hand is a continuation of the line of the whole arm and the palms face forward.

In Chinese dance, the purpose of hand gestures is to emphasize movement that tells the story, or to emphasize symbolic and aesthetic beauty. For example, in Pickup up the Jade Bracelet, the solo dancer gestures to open the gate. The whole scene is in pantomime, using a lot of hand gestures as symbolic movements in the dance. In addition, there are circular and cross over movements in space. Circular movements ranging from small to large can emphasize design. For aesthetic purposes, hand gestures are created by emphasizing the rotation of the wrists.

In modern dance, arm and hand gestures will vary, based on the theme or idea. Unlike Chinese dance, modern dance emphasizes total body language rather than individual hand gestures. Modern dance is also freer and more open in all arm and hand movements.

Step

In Chinese dance, step means the way legs and feet move within their codes. Modern dance does not have any specific rules to follow. It can adopt any type of dance step, or create new steps to fit its theme or idea. The techniques of both Chinese and modern dance are used in a similar manner to ballet's precise steps, but require different demands from the dancers. As in ballet and Chinese dance, modern 
dance movement is performed in the air, on the floor, and in varying directions. However, modern dance allows more freedom in interpretation of technique.

A few of the movements that each dance style has in common are: "À La Seconde Développé ": the foot at the knee, then the lower leg extends to the side. "Relevé": raising the heels from the floor. "Arabesque": the leg extended to the back and off of the floor. In Chinese dance, "Arabesque" becomes square, arms open side to side and feet are turned parallel. The name of this movement comes from imitating the shape of the wild goose, it is called "She Yen" ( which literally translates to "shooting the wild goose." In Chinese technique, the term "À $\mathrm{La}$

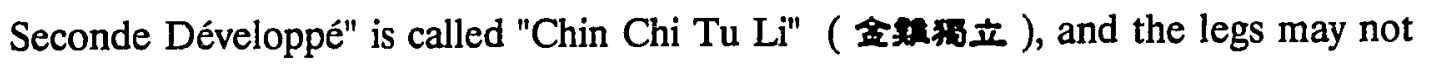
necessarily be turned out.

Steps in Chinese movements are also divided into these 10 groups:

1) "

2)" "

3) "

4)"

5) "
Tie foot Step: either walking or running, heel toe with same size, speed, and range of step. Knees are bent and always touching each other.

Tread Step: one foot forward then the other close up with knees touching, keeping them bent with the sole of the foot, but not the heel on the floor.

Stride Step: left foot steps to left side, right fcot over to left foot with the right tip of the toe on the floor, both knees are a little bent.

Cloud Step: travelling to the side, both legs turning inward then outward, both feet retain contact with the floor throughout.

Slip Step: same as Chassé in ballet (a sliding step), but 
steps are quick and small and close to the ground.

6) "

7) " 趣步"

8) " 花而子步 "

9) " 斜步 "

Slip and Sink Step: a combination of Chassé and Coupé (a quick transfer of weight from one foot to the other in the same spot). Quick and small Chassés at a low level, landing on one foot. In both movements, the knees are bent, and touching.

Tendency Step: the first step, right leg toward right, is slow followed by a step with the left leg which is small and placed behind the right leg.

Flower Step: same as Bourreé in ballet (a running step on half or full pointe with both feet very close together). In Chinese dance, the feet are flat and the legs are parallel. The movement is to the side or to the front, with both arms crossing and opening in front of chest.

Inclination Step: side walk with torso slightly turned to face a diagonal.

10) " " Ghost Step: Bourreé on half pointe in a parallel position. The bent or straight legs are either at a low or high level, with the body moving forward or backward, as well as sideways. During walking, the head, torso, and arms (dropped at side) should depict a floating-like-a-cloud feeling, with a slow to quick tempo.

\section{USE OF SPACE}

Focus

Direct focus is used to emphasize a particular movement, or important point in the dance. This applies to modern dance as well as to Chinese dance. The difference between focus in Chinese dance and modern dance is in how the focus is used. For example, in Chinese dance, the dancer's focus is on arm movements, the 
audience, or other dancers. Chinese dance uses a different focus for each attendant movement, depending on the content or meaning of that movement. In Chinese dance, focus is more controlled and restrained, as opposed to the focus in modern dance where the dancer relates in a diffused way to the stage space, or other dancers, or the audience.

Another use of focal points is for the dancer's own projection. This technique in Chinese dance is called "Liang Hsiang." "Liang Hsiang" is a pure, simple action using intense, sustained internal energy which brings the torso, head and eyes to a specific focal point creating a powerful image. The focal point may be on the audience, another dancer or an object on the stage. Sometimes in Chinese dance, the dancer's focus is on the arms and will follow the movement of the arms. Modern dance focus may also be the same as in Chinese dance. In addition, it may encompass an area rather than an object, focus on a particular spot on stage, or be used to highlight a dramatic idea in a dance.

\section{LEVEL}

The use of level in Chinese dance is the same as in modern dance. Generally Chinese dance is performed at a standing level. A standing level with straight legs (middle), represents being on the ground (or stage) rather than into the ground. A high level is in relevé or in the air. It represents flying and a defiance of gravity. The floor level (low), represents earthiness, going into the ground. It has a strong sense 
of gravity. For example, walking on the knees is a movement used to depict requesting and begging in Chinese dance. However, walking on the knees in modern dance may have additional meanings. In the Chinese warrior dances, in which a story is being told, one will see many movements on the floor to depict fighting skills. Sometimes, in both Chinese and modern dance, floor movements will occur for the purpose of displaying strong feelings such as anger, sorrow, or hostility. Additional movements at the lower level can be found in acrobatics. This is very prevalent in Chinese dance. Such acrobatic movements display skills such as back bends, walking on the hands, handstands, cartwheels, flips, splits, somersaults, and rolls. Modern dance may use these acrobatic movements to depict an idea rather than to display an acrobatic skill. All the levels in modern dance are used more freely than in Chinese dance, which uses them with more specificity.

\section{Group Formations}

An important element in Chinese dance is group formation. This is the overall shape of a group of dancers when they move as a unit. In Chinese dance, you will often see dancers in straight, diagonal and circular formations. The form is very regular, very balanced and equal. It is important that the straight lines are not broken. A formation must be complete (i.e., circles, horizontal lines and diagonal lines). This is an attempt to place bodies on the stage that will show a balanced unified image. There are no attempts to use asymmetry because it would create 
conflict in the visual image.

Another emphasis and purpose in Chinese group dances are the grouping of people together. This grouping symbolizes power in Chinese culture. This emphasis is more important in Chinese dance as opposed to modern dance, which generally emphasizes the individual dancer. For example, circles are prevalent in Chinese group dances. They are symbolic in Chinese culture and represent the joining together of two. The circle is a symbol of unity, a common theme in ancient Chinese societies. This is not necessarily true for modern dance. The circle is used but it may not be for symbolic reasons. Whereas, in the Chinese culture, the circle is a meaningful symbol and will frequently be used. Also, curved lines such a figure eights, and shapes of $\mathrm{S}$, can draw a pattern that the Chinese believe is a symbol of luck. Therefore, Chinese dances use circular and curved patterns in dance formations for symbolic reasons as well as for suggesting group unity.

Modern dance will use a variety of formations which often have no symbolic meaning. Although curved formations and regular lines are used, there is more variety. Modern dance formations show less emphasis on straight lines and more on irregular shapes, such as lines or shapes placed off-center or juxtaposed against each other. Other group formations used in modern dance include triangular and other geometric masses.

Balance, like symmetry, is also a major consideration in the shaping of designs in Chinese dance. Balanced images are considered to be important in Chinese life 
and philosophy as well. In relation to the whole work, if a solo dancer is a part of a group work, the solo is treated separately. The chorus poses or follows the soloist's movements while the solo is being performed.

\section{Design in Space}

Another element found in Chinese dance is the prominent use of group design or static poses. These pictures or poses can be found in various places in the dance. Usually there will be a movement sequence and then the dancers will end the sequence in a pose. This is common in Chinese dance and originates from Chinese Opera technique. The purpose of the group designs are twofold: 1) clarity of the idea, and 2) imitation of animals. The still poses represent a symbolic gesture of unity by using still movement designs. The circle formation, which is concentric, is a symbol of luck. Such designs are preferred and emphasized. The final images remain and state clearly the idea intended for the piece. Body designs are primarily shown in curved lines, as in the sequence of "Shuan Yao," where the torso swings in a circle from side, front, side, back. During the "Shuan Yao" process, arms, feet, and torso appear in a harmonious curved line with internal sustained energy. These soft movements are momentarily frozen into poses which become powerful.

The second purpose for the group poses arises from historical traditions. In ancient times, Chinese dance imitated a lot of animal actions and many designs show these animalistic gestures, such as in the familiar Lion Dance. 
All designs are symmetrical. It is believed that symmetrical group formations bring joy to the vision. For example, two people on one side of the stage may be positioned with the same gesture while two people on the opposite side will mirror this gesture. Therefore, symmetry is primary in group formations which emphasize balance and a joining together.

Modern dance choreography may have the same designs as Chinese dance, but frequently forms are also asymmetrical and broken. Whereas Chinese dance designs may be more literal in the choice of shapes, such as in an animal dance, modern dance designs are more abstract. Bolm and Chaplin describe design in their book, The Intimate Act of Choreography:

Design can be thought of as a capturing of form. It can be static, as in a pose, tableau, or position that is breathlessly on the verge of arrival or departure. But in can equally be perceived as dynamic, having the cumulative effect of a tracing of motion; for Movement moves and disappears by the time we can register it to be captured in the memory only as a stillness of sorts, a movement picture (Bolm \& Chaplin, 37).

\section{THEMATIC IDEA AND FORM}

The form of Chinese dance falls into three basic categories: following the storyline, following the music structure, or following the demands needed to perform skilled technique.

Dance following a storyline refers to the dramatic or narrative form of dance. This form is based on using elements required in advancing the story, such as in The 
Tale of the White Serpent. When a dancer introduces the story at the beginning, he/she presents movements that characterize the dancer's role for the story. The plot of the story determines the idea of the dance and creates the form of the dance.

Many Chinese dances are based on a feeling or metaphor, such as the Chinese fan dance, Spring Evening on a Moonlit River. If the dance is based on an emotion, the form of the dance closely follows the structure and the quality of the music.

Many Chinese dances are composed for the purpose of displaying the skill of the dancers, for example, the Red Ribbon Dance which symbolizes celebration. The form of this dance is based on the way the technical movement is created. This may also require the use of props such as in the Lion Dance, which, like the Red Ribbon Dance, requires technical skill and the use of props.

Modern dance is similar to Chinese dance in regard to the thematic idea or the use of metaphor or technical skill. As Bolm and Chaplin state in The Intimate Act of Choreography: "It is possible to produce as John Martin says 'An aesthetic effect through form rather than through content.' So form can serve dualistically-either to carry the message or be the messenger itself." (Bolm \& Chaplin, 84).

Bolm \& Chaplin describe form as the following: "Form existed and humans conceptualized, abstracted, and then incorporated it into their own creations, into their highest expressions about life into art" (Bolm \& Chaplin, 84). Modern dance is more flexible and is not subject to the rigid, restricted rules of interpretation found 
in Chinese dance. A given theme can have any of several treatments and may be represented in abstract style and form. In Chinese dance the form reveals a very steady progression to the end of the piece and has no climax. Modern dance differs by extreme change, or by even the sudden cessation of movement, in order to reach the climax.

\section{STYLE}

\section{Cultural Style}

The style of the Chinese dance reflects the culture of the country. Dances express the country's social customs, religious beliefs, and philosophical ideals.

Chinese dance reveals cultural styles of the country through the influence of certain facts. For example, women in ancient times were portrayed as having virtuous behavior. Therefore, the style of Chinese female movement shows small, gentle, controlled, and restrained movements that indicate femininity. Such choice of movement is one example of how social customs may have a bearing on the choreography. It might also be possible that the behavior rules of the society in ancient times had an impact on the types of movement found in Chinese Opera dance. For example, there were exact rules for walking movements. In one movement, the legs are parallel with the toes of the back foot following the heel of the front foot, almost touching. The movement is done with the knees bent, the knee of the back leg almost touching behind the knee of the front leg. During the 
sequence of movement, the walking should always keep the same level and maintain a controlled intensity. This creates a vision of floating and elegant movement on the stage. Another rule for Chinese women to follow was to always look downward, especially when meeting senior people or people whom they have never met before. Dignity was very important for a well-educated girl brought up in a good family and such a rule was standard. In ancient times, society did not allow women to go out. Bound feet, traditional in the Ch'ing Dynasty (1616-1912 A.D.), created small steps and related movements. These steps influenced the female movement in the Chinese Opera dance and transformed it into a series of elegant movements and gestures. Perhaps these rules reflected the culture of the time. For example, in the ritual music of the Chou Dynasty (1122-256 B.C.), the official in charge of music and dance focused on how to cultivate moral principles of equality, impartiality, filial piety and brotherliness.

Chinese philosophy toward art should also be considered in evaluating Chinese dance. Chinese philosophy and religious ideas regarding beauty, balance and harmony may be reflected in the use of smooth and continual movement in Chinese dance. Circular, soft, endless, tender and small movements indicate humility and were standard rules for the female to follow in ancient China. The artist strives for symmetry, harmony, purity and silence of movement. In Chinese philosophy, gentleness is a treasure.

Political influence may be seen in many Chinese dances, especially the 
influence of Soviet philosophy arising from the Cultural Revolution in China. Traditional dance was transformed utilizing ballet movements. The Chinese dance became a form for presenting the new ideology. For example, the Red Detachment of Women served as a model of the goals and values of the ruling group. In dances reflecting this, movement became larger and more powerful, and included great leaps.

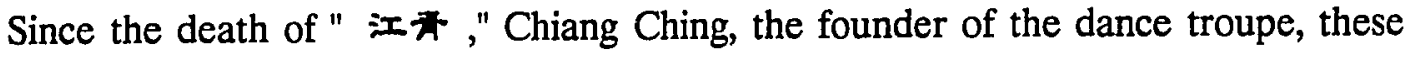
dances are no longer performed.

The style of modern dance is determined by historical time frames, personalities, body types, and cultural values. Personal movement style was the starting point of producing the codified techniques that exist today. It is essential in modern dance that a person's movement style always be uniquely expressive of the whole person. Personal movement style is individual and comes out of the choreographer's experience and training. This personal style is prevalent in modern dance, and is not found in traditional Chinese dance. In modern dance, the choreographer can use any cultural style as raw material for choreography without trying to reproduce authentic ethnic movement.

\section{DYNAMICS OR QUALITY OF MOVEMENT}

The use of endless-timing and repetition contains the use of internal sustained energy in Chinese dance. Since movement is performed in a circular path, body designs are primarily shown in a curved line creating a quality of gentle movement 
such as "Wo-Yu." Conversely, a gentle movement quality is able to transform the strength of a movement, such as "Tao Tzu Fan Shen." In this movement, the body continues to turn as the back arches like a windmill. This is an internal sustained control of energy from the center of the body. This combination of strength and gentleness becomes the essence of traditional Chinese dance and music.

Externally, Chinese traditional dance is a combination of strength and gentleness, a range of small to large movements and a combination of fast and slow. The following categories can be utilized: 1) time--slow to fast; 2) size of movement-small to large; 3) quality of energy--soft to strong. The combination of these categories is termed dynamics and can also be seen in modern dance. For example, small movements, such as fast running steps executed intensely and precisely with flexed toes following the heels, will give the appearance of strength on the stage.

In modern dance, dynamics emphasize force (energy) with time and size of movement. These qualities take place in the physical body. Movement quality, as defined by Bolm and Chaplin, is the manifestation of time and force produced by the body as it moves. "Movement qualities can be categorized as Valerie Hunt does (into burst, undulate, sustained, and vibratory), or they can be the grand umbrella under which every type of movement from apelike to zigzagging falls" (Bolm \& Chaplin, 77).

The elements of dynamics, or qualities of movement, are the same in both styles, although Chinese dance is more restrained and continuous, while modern dance offers more variety. 


\section{MUSIC}

Quality of Chinese Music and Timing

The incorporation of music and dance is essential in Chinese tradition. There is a Chinese Opera saying: "Every word spoken is singing and every movement is dancing" (Chinese Art, 174). This is a good interpretation of Chinese music and dance. In modern dance, music can have tremendous power in determining images and the resultant movement for the dancer. The sources of dance and music can be used to help achieve the choreographic intent.

Music in the Chou Dynasty (1122-256 B.C.) was characterized by ritual music. The official music teacher focused on how to cultivate moral principles as well as on how to dance. The perception of time is endless, not only for the music but also for the dance. Respecting the beauty of time is also important. Timing-endiessnessrepetition was always the code that ancient dancers used to signify happiness and harmony in the dance. For example, arm movements perform continual synchronized circular paths. Of course, repetition is essential in this affair. Therefore, the rhythmic structures used in Chinese dance and Chinese music emphasize continual flow and non-metered movement. Stillness is constantly used to emphasize and clarify important parts of the movement. This will bring the same results as accents do in modern dance.

The tempo of a piece will stimulate and reflect the choreographer's dance style. The combination of rhythms is what distinguishes different styles of dance. Originally 
the Chinese believed that music reformed people's manners and customs. The beat goes fast, or the beat goes slow. These are determined by the response and attitude of the dancer in the dance. A rapid tempo can cause the dancer to rush, bringing in conflict or excitement. The slow beat indulges sensuous pleasure or gentle caring, or can be painful or sorrowful. Sometimes the speed of the beat starts intensely and finishes in slow tempo, such as in ritardando. This suggests the return to normal.

A regular beat of music can be supportive and comforting to the audience and is used often in Chinese dance. In modern dance, a regular beat is especially helpful in partner and group work where it functions as a unifying force, keeping everyone's timing synchronized. Conversely, an irregular beat of music is unpredictable and is prevalent in modern dance more than in Chinese dance. A modern dance choreographer will utilize the music's conflicting, disjointed, surprising, annoying, or comic effects in a variety of ways. Chinese music, as well as Chinese dance, is not as complex in this aspect.

\section{METHOD}

The way movements are performed is called method in Chinese Opera dance. In modern dance it is called performance technique. Although the way to utilize and achieve it may differ, the result is the same.

The method of performance in Chinese dance includes an inner momentum 
that emanates from the character and an outward momentum that comes from the hands, eyes, and body cooperating together. This leads to steps that may include walking, turning, shifting, kicking, or jumping. These rigid organizations of movements should have enough strength and flexibility of body as well as a combination of strength and gentleness from within. As a result, the body cooperates with suitable gestures that include torso extension and focal point. This promptly produces the method in the performance.

In modern dance, the performance method is determined by the individual choreographer. The performance requires technical and performance strength. The performance may need stronger movements than Chinese techniques to allow the body to freely move in irregular and short-time and to change positions and extensions of movements. In addition, in steps of elevation the dancers may give the appearance of giving into, as well as defying, gravity. The use of method in the performance of modern dance does not follow rigid rules as in Chinese dance and, therefore, is more creative than Chinese dance and presents a different kind of a challenge for the dancers.

\section{THEATRICAL ELEMENTS}

\section{$\underline{\text { Props }}$}

In Chinese dance, props have symbolic usages. Symbolism is an important characteristic of Chinese Opera as well. One example is using a whip to portray 
riding a horse. Female dancers use fans but not for practical purposes; playing with a fan in the dance suggests a charming, or feminine, beauty. A man using a fan shows flirtation, or a person who is at leisure. Sometimes it suggests a man thinking or meditating.

In a "fight" scene, artificial weapons, such as swords, spears, shields, and pikes made of wood, bamboo, or rattan, are used merely as symbols within a dance that is primarily acrobatic.

In modern dance, theatrical elements, such as props, are used in similar ways but may be found less often than in Chinese dance. Martha Graham in the Bolm \& Chaplin book, The Intimate Act of Choreography, refers to sets in her modern dance as characters, powers on the stage and not merely decoration. They may, therefore, be used in a symbolic way, the same as in Chinese dance (Bolm \& Chaplin, 193).

\section{Costumes}

Chinese dances do not vary according to season, period, or locality. As for period costumes, all kinds of dresses are supposed to be based on styles from ancient times to the Ming Dynasty (1368-1644 A.D.). A suit with a jacket and skirt is worn by young maidens or women of wealthy families, and a jacket with trousers is for girls from poor families. Only the Ch'ing Dynasty (1616-1912 A.D.) has a special costume for the female role: the Ch'i Pao, a long embroidered gown. Pheasant plumes and fox tails are worn by the dancer who portrays either a barbarian or one who lives in the 
barbarian region. The idea is that the barbarians come from the cold north and are experts at hunting, so they use plumes for their decoration and wear fox tails to resist the cold weather. However, wearing these decorations also suggests the personality of the character. The style of costumes depicts ancient time periods. Costumes are not exact replicas of the original costumes but designed to suggest a definite time period or dynasty.

Use of color in Chinese costumes has symbolic meaning. Costumes of yellow are worn only by the emperor. Red material suggests a happy occasion, such as a wedding. Black indicates low financial status, or inferior people.

In modern dance, the features and styles of the costumes can depict the difference between generations. Choreographers use costumes to enhance and clarify their ideas and help the audience to understand the dances. Costumes can serve another purpose: to extend the real and illusory design possibilities of the human body in movement, such as in Nikolais's Image.

\section{Headdress}

There are a lot of headdresses for Chinese dance. Each fits the personality and social status of the character that is impersonated. Emperors and empresses wear crowns. A respectable prime minister wears a square hat, while a traitor wears a round-topped one. The wife of a noble wears what is called a Phoenix Hat, shining with jewels, while a poor woman in a black garment wears cheap ornaments. Special 
hats are designed for warriors, fishermen, hermits and other characters.

Modern dance uses less headdresses than Chinese dance, and may be, except for design purposes, found in dances where characters and historical periods are conveyed.

\section{Make-up, Painting Faces and Masks}

To emphasize Chinese female characteristics, dancers copy the female role (Tan) make-up from Chinese Opera. Dancers will paint their faces in white and then surround their faces in red tint which gradually becomes pink on their faces.

Male facial paintings are most fascinating and significant in Chinese Opera. Each type of face symbolizes the personality of the character. A red face suggests loyalty. A white face indicates a treacherous person. A black face suggests an upright person. A face painted in black and white represents a courageous but careless person. Green, purple, or reddish faces are either bandits or evil spirits. Golden faces display gods or supernatural beings. Face painting originated from the mask worn by Prince Lan-Ling in the sixth century to scare away his enemy. There are only a few occasions to use it. The character who depicts the "God of Fortune" wears a mask on this occasion to celebrate Chinese New Year. Another occasion would be when the fairies go to the "Heavenly God." Ghosts put on a dreadful looking mask to frighten people.

In modern dance, facial paintings and masks can also be functional or 
decorative. They can be used to draw attention to one particular part of the face, such as the eyes or mouth. Masks can be used for proclaiming neutrality or establishing identification. However, the use of masks or specific color is not as important, nor is it required, as it is in Chinese dance.

Regular stage make-up for Chinese dance is not different from modern dance. Simple make-up enhances the dancer and improves the audience's discrimination of facial definition and expression.

\section{$\underline{\text { Lights }}$}

The lighting for displaying the skill of Chinese dance is very simple. Lights in dramatic performance depict aspects of Chinese life and sentiments by using only white (bright) light to reveal the characters in the story. On the other hand, the Chinese Dance, Spring Evening on a Moonlit River, is based on a feeling and metaphor. Lighiting creates an atmosphere to serve the choreographic need as well as to enhance what the audience sees.

Lighting in modern dance creates and defines the space that effects which part of the stage is prominent and also directs the audience's attention. It also can create space, isolate one place from another place, and also define space, such as warmfriendly, or cold-dangerous. Any change in lighting causes an automatic psychological response in the viewer. 


\section{CONCLUSION}

The following elements have been described in the above chapter for the purpose of noting differences and similarities in Modern dance and Chinese dance.

The choice of movement, style and method of performance, thematic idea and form, quality of movement and music, various usages of the dance space and the use of theatrical elements are the described categories. These elements will be used in the next chapter for the purpose of explaining the choreographer's intent for each dance in the concert. 


\section{CHAPTER III \\ DESCRIPTION OF DANCES}

\section{Enlightenment-solo}

The dance presented the image of a Chinese dancer going through a spiritual transformation relating to one of the Chinese religions, Buddhism. The choreographer used general concepts of Buddhism involving the philosophy of birth, aging, illness and death, by emphasizing the use of harmony and nature. Buddhism in China reveals the ideal state in which the individual self is united with the supreme spirit, Nirvana, and shows the state of harmony and bliss that is essential. Nirvana is defined as "the state of perfect blessedness achieved by the extinction of individual existence and by the absorption of the soul into the supreme spirit, or by the extinction of all desires and passion" (Webster's New World Dictionary, 962).

At the beginning of this dance, the dancer was kneeling in the upstage corner representing a human state. The dancer used curves and angular lines to suggest the state of aging and illness. The dancer then stood up and progressed to the center and proceedcd to fall with sharp and quick movements. The dancer then rolled into a stiff position to suggest the condition of death. When the prop, a red sheet, changed from the plain to the shiny side, the movement changed to a smooth " $\mathrm{S}$ " quality. At that point, the transformation of changing from aging and illness to a state of birth and joy began. The dancer kneeled into a parallel, angular pose to praise Buddha. Following this climatic point, the dancer continued in this joyous state to the end of the dance. 
The dance ended with the dancer exiting upstage right in a single path of light, signifying the spiritual transformation.

The theme movements were chosen through the use of curved and angular designs, which were drawn from modern dance vocabulary as well as from Chinese dance technique. Movements used in the curved designs were circular and contracted. The movements went around the torso, and swayed toward or away from the center of the body. As the dancer knelt, the angular designs occurred. Other movements were created using a ninety degree angle. Chinese dance technique was selected to show the transformation. One selection was the traditional celestial Chinese dance movement, moving in the figure of "S." The moving of angular parallel lines was also selected to praise the supreme spirit and to reflect the image notable in many Buddha sculptures. These Chinese dance movements were created by using open, large and extended movement.

The transformation was also shown by the change of energy or quality of movement. In the dance itself, the quality of movement from the beginning was different from the quality of movement shown at the end. The dancer showed a gradual spiritual transformation from the beginning to the ending of the dance. For example, at the beginning of the dance, the quality of movement was chosen to show the dancer as humble and depressed. This was accomplished by the use of small, contracted, and released movements when the body moved to or away from the floor. The body swayed slowly, contracting and releasing, then lowered to the floor to 
suggest sadness. At the end of the dance, graceful, subtle, precise movements, complete with reaching out, were used to praise the birth. The transformation was also shown in the contrast of size of movement (small to large) and the change in timing (slow to quick), which resulted in changing the total quality of movement.

The prop for Enlightenment, (a $4 \times 8$ piece of material) was used as a symbol to show the transformation from normal to supreme; one side plain, the other side shiny. The plain material represented an ordinary life showing birth, aging, illness, and death. The shiny side of the prop represented the achievement of the supreme state of harmony and bliss. Red was used for the prop because it is an Oriental primary color representing good luck and passion.

The solo dancer wore a flesh colored unitard. The purpose of the color and plain costume was to present the dancer as neutral in gender and to interpret a Buddha figure that could be male or female. The skin colored unitard, the make-up, and the headdress were unadorned and simple to suggest the nature of Buddhist philosophy.

Nostalgia-duet

The intention of the choreographer was to reflect the change of Taiwanese women who have been influenced by Western culture. This present experience could be best interpreted by using modern dance style.

In this dance, a young woman recalls her childhood in Taiwan and realizes her 
experiences as a child in Taiwan were different than her experiences now. Today, Chinese women are freer than they were in the early Republican years and are allowed to work in the outside world. This new independence in these new environments has given women more respect, as well as a challenge, in their society.

This dance was based on the music of a Taiwanese folk song which was recalled from the sixties generation. The melody itself had strong dynamics and moods. The music brought back past memories. This expression of music was what the choreographer wanted to interpret.

At the beginning of the dance, in silence, there was a dreamlike situation. A man and a girl lay on the floor, then sat up at various times looking at each other, each in different timing. This was repeated again and again. During these contraction and release movements, the man showed the girl a windmill which represented their childhood. Simultaneously, the music started and the girl jumped up to the man's back, then fell to the floor, crawling and crawling again. The man walked up to center stage and the girl ran to join him. Silence! Their steps built from small to large while they twisted their torsos. The traditional Chinese small steps, with "tie feet," were subtle and became faster and larger to represent Western cultural influences. Then the man lifted the girl up to the ceiling and circled down to the floor again. Use of contracted movements into still poses showed frustration for both of them, one in high level, the other one in low level. This frustration continued in the next section. She again, quickly and strongly, stood up from the 
floor, while the man slowly moved down to a low, squatting position. The man stood and walked with his torso arched and his head back. He then went into a contracted jump in the air. Following his landing he stood still. The man and girl stood away from each other, then walked together using strong hand gestures to suggest their loss. In the following parts, the use of extended hand gestures and continued poses in the dance were selected to suggest an image of endlessness. Sharp poses and jagged movements were also selected to suggest the courage of both the man and girl. The dance itself resolved the conflict for the couple because it allowed them to experience freedom found in the values of the West, as well as to understand the process of growing up in a traditional Chinese environment. The use of the windmill recalled good memories of their childhood.

The use of dynamics, focus, and hand gestures were emphasized in this dance. In dynamics, a quick speed and change in direction were selected to contrast the continual movements such as: slowly going down then quickly standing up, or breaking down a series of sharp poses. The use of dynamics could also be found in extreme and immediate changes in level, such as moving from a lying position and immediately jumping to the man's back, as well as in the use of silent, still poses contrasted with quick movement, and small steps (tie feet) contrasted with large steps. This could be seen when the man lifted the girl in the air, brought her down to the floor, and immediately went to a still pose.

Focus was used in various ways in this dance. This was accomplished by using 
a direct focus towards the audience or towards the completion of the still poses. For example, when the girl crawled toward the front of the stage, while moving on a diagonal line, her focus towards the audience never changed. Sometimes the focus followed the movements as the poses changed.

The hand gestures were selected to emphasize the continual movement. For example, continual movement was used to depict both an image of endlessness, and to suggest a remote distance, as if the female was looking for her hometown. The movement and the use of dynamics and focus were choreographed in modern dance style to help project the Chinese theme and music.

\section{Enchanting Celestial-group}

The intention of this dance was to present a traditional Chinese dance. It was a group dance in three parts. The five girls who danced were called "Celestials" performing in an idealized Buddhist heaven. This type of dance was brought into China in the Northern Wei Dynasty, 534-550 A.D. It was called "Celestial" to indicate that the dancers were mystical even though their wings were discarded and clothing had been added. These "Celestials" danced the praise of Buddha. Many of the movements reflected the paintings and sculptures taken from the caves of Tunhwang, a treasure house of Buddhist scriptures and paintings. This dance was based on Chinese music which was adapted from "Tunhwang" music of an ancient time. The music was composed for "Celestial," the girl who danced in heaven to praise Buddha. 
The music itself was harmonious and serene. The movements and formations in the Chinese dance were generally of even tempo and were balanced to relate to this feature of the music. To create a contrast to this balance, the tempo of movement was occasionally varied.

The dance started with five dancers on stage left. Dancers in this dance represented the dancers of Buddha who showed various dancing statues, poses, etc. The next section was a solo presented by one "Celestial" dancing in praise of Buddha. The dance was built on S-movements, which were used throughout, a tradition in Chinese dance. The last section returned to the five dancers. This section presented various images of Buddha with different types of hand gestures as found in "The Thousand Hands of Goddess of Mercy" ( 千手㱐 ).

In the beginning of the dance, the girls walked and posed in different directions to introduce themselves and to emphasize their characters. The dancers used curved lines with their arms, torsos, and fingers in various poses. They used various movements found in the technique for the female dancer in Chinese dance, such as the turning of the torso in a pinwheel movement called "Yao Tzu Fan Shen," and arms in a semi-circle design called "Shan Pang." Their focus, called "Liang Hsiang" in Chinese technique terms, always followed their arms and then changed back to the audience. The solo dancer used primarily "S" movements in her torso. For example, she emphasized and shifted her pelvis and then the rest of her limbs followed, which build "S" lines in her torso. In the last section, dancers placed both palms close 
together as if praying, or spread their fingers out as if taking a flower. Both hand movements were utilized to emphasize Buddha's teachings and to show beautiful forms.

Many circular formations were used throughout the dance. The use of formations in this dance were even and balanced, such as spreading out from one horizontal line to a semi-circle, or squeezing into a small circle then opening to a square.

\section{Horizon-trio}

The intention of this dance was to maintain the Chinese sense of infinite space and distance, as in the special style of Chinese painting. This style of Chinese painting utilizes few images, leaving large spaces which represent freedom and give an impression of endlessness.

The choreographer also intended to present a love triangle (two girls and one man), and to show the conflict between them. The conflict was resolved when each person went his, or her, separate way.

This dance was choreographed in pure modern dance movement. The characters in this dance reflected the desire for freedom from the early Republican years, when society treated women as inferior to the male and taught that humility was the nature of women.

The use of simple movement was selected in Horizon to emphasize the power 
of silence. For example, a basic dance walk, a simple hand gesture to cover the eyes, a drop of the head to the shoulder and a simple reaching gesture were used.

The thematic movement reflected various symbolic movement images. The use of the hand covering one side of the face was a movement gesture to indicate difficulty in making a decision. To demonstrate that people make mistakes, this gesture showed conflict within the self. This thematic gesture was repeated throughout the dance, starting with one dancer, later with two dancers and lastly with three dancers.

Another theme movement used in the dances was the dropping of the head to the shoulder. This movement gave the impression of depression, and a resigned, reserved, and passive reaction to the specific circumstance surrounding each individual, thus creating a feeling of hopelessness. The movement was used throughout the dance, sometimes by one and other times by three dancers.

The simple reaching gesture used a soft and weak quality of movement. This movement was selected to indicate a longing for an ideal and the struggle in accomplishing that goal. The body movements used the contrast between straight, upright, and stiff lines, and curved, released and broken lines, resulting in a melted quality of movement in order to reveal their contradictions. Other similar gestures includer the theme idea of reaching with the image melting to show the same reservation as mentioned above. These movements were mostly initiated by the first dancer. 
Various group images were used throughout the entire dance. The use of body design and created forms brought forth various images. For example, one image utilized the use of lines and stillness. Three dancers stood in three vertical lines then used two curved lines to contrast the vertical line. This contrast was used to suggest difficulty in the dancers' relationships, as well as the use of stillness within the movement phrase. Another image utilized overlapping vertical body lines of two dancers. The image of the girl's head dropping from side to side was used to suggest a hopeless situation. Only simple movements were utilized to create the various images.

Another approach in developing strong visual images was used in the second duet and dealt with contrasting body design and weight. In order to give the audience the impression of conflict, the girl's body weight, as she hung on the man's back, created a burden as the man walked forward. This image involved the use of weight and design to indicate the inability to support each other.

Another approach in creating different visual images was used in the first duet. The intention of the duet was to suggest the image of the woman's broken heart. These images were created by using disconnected movement and broken lines in body design. Movements were also distorted in an effort to break the perfect classical line. The lift showed the contrast oi a classic line with a broken line. The male used a strong line while the girl's torso and limbs showed broken and melted lines.

Another example in contrasting approaches to various images was used in the 
basic walk at the beginning of the dance, and the upright bodies at the end of the first section. Images were created by the dancer's constant change in direction. This created a contrast between stillness and action-changing directions, thus creating strong dynamics in the dance.

The breaking-up of movement utilizing the contrast of slow and quick movements were the dynamics used in the dance. For example, the dancers quickly stood up, then immediately began a slow melting movement, or the dancers started with a slow dance walk, then ran sharply into a fall, quickly rebounding to complete stillness. Sometimes, the breaking-up of movement by changing directions or focus was used to increase dynamic change.

The form of the dance was ABA. The music was chosen to enhance the mood of the dance. The choreographer chose this music because of the continuous single melody throughout the whole piece. The melody was quiet and doleful and allowed a lot of possibilities for creating various images and movements. The choreographer repeated the entire musical piece to extend the dance, matching the movement quality to the quality of the music.

\section{Dream of the Red Chamber-group}

This group piece was an abstract interpretation of the well-known Chinese novel, Dream of the Red Chamber and was an attempt to blend Chinese classical dance with modern dance. In contrast to Horizon, this tragic story shows the 
traditional values of China.

Chinese traditions are reflected through the Chia family, of which a good example is summarized in the book, Dream of the Red Chamber:

Mirrored in this many-peopled chronicle of the Chia family is the fascinating picture of China where members of a great menage lived together, all the sisters and brothers, uncles, cousins and aunts. Graciously, in spite of sorrows and misfortunes, their lives glided into years, in caring for the sick, burying the dead, honoring their traditions, maintaining their loyalties, laughing a little, and loving much (Dream of the Red Chamber, Jacket Notes).

It was the intent of the choreographer to synthesize this story into a dance

form. The dance centers around the three characters, Black Jade, Precious Virtue, and $\mathrm{Pao}-\mathrm{Yu}$, showing their relationships and conflicts.

This dance was choreographed to the Concerto \#2 for Piano and Wind Ensemble by Brent Heisinger. The dance started by introducing the three main characters, Black Jade, Pao-Yu, and Precious Virtue. The first solo introduced Black Jade. Black Jade came to the Chia family when her mother passed away. This dance was created to show her personality and character. This section also included a "flashback," showing her relationship with a god from the realm of the dead. His following of her was to suggest her forthcoming misfortune. The next solo introduced Pao-Yu, who was a partner with Black Jade in the previous generation. The dance was created to show his character and personality. Pao-Yu is the leading male dancer and the center of the love conflict. The third solo introduced Precious Virtue, who 
is the second woman within the love triangle. Her entrance is presented in a dreamlike image of a wedding procession. This image was a symbol to foretell of future events yet to come. The dancer riding high on the shoulder of a dancer camouflaged by a red cape indicated financial status.

Movements for the three main characters were chosen to interpret each one's personality. For example, Black Jade used a soft and slow quality of movement to indicate her weakness and sensibility. Sometimes small and quick movements were used to show her personality. Instead of strong movement, Pao-Yu's curved movements were selected to show his gentle character, and to suggest his respectful and caring nature towards the maidens. Precious Virtue used a quick and strong quality of movement to portray her success in dealing with people and to indicate her tactful character.

The next section was a group dance and presented as if in a dream. These were the twelve maidens whom Pao-Yu previously lived with in "Takuanyuan." Each dancer represented a particular flower which corresponded with their names. This is common in Chinese culture. The movements for the chorus were chosen to create harmony. Similar movements were repeated in different timing and different group formations. The chorus dance was in rondo form. One dancer entered, then two dancers and then a trio. After the trio, the rest of the chorus joined and completed the movement sequence. The formation used for the chorus utilized Chinese techniques and formations, such as thirteen dancers standing in horizontal lines, or 
two parallel lines, and in circular formations. Many poses were used to clarify the theme and storyline. The chorus movements were chosen to emphasize unity, common in all Chinese dances.

Gradually, the center stage left only Pao-Yu, Black Jade, and Precious Virtue in a love triangle. The merement in the trio was inward and limited, indicating their conflict. Dancers moved minimally and focused away from each other. Curved movements were primarily used rather than angular. A duet followed the trio showing Pao-Yu falling in love with Black Jade. The next section was the wedding, where Precious Virtue marries Pao-Yu instead of Black Jade. This was indicated by the dancers changing their capes. Precious Virtue wore Black Jade's cape to disguise herself as Black Jade. The use of this disguise, to trick Pao-Yu into marrying the other woman, was also supported by his family.

The last section of the dance showed the disorder and decline of the Chia family, the death of Black Jade, and the exile of Pao-Yu to a monastery. The chorus represented spirits, rather than maidens, to suggest the misfortune of the Chia family. The modern dance movements selected for the chorus showed imbalance and disharmony. The opposing forces created the dynamics. Dancers as a group had individual, but similar movements. Capes were not used in this section. Unitards gave a modern abstract impression to suggest spirits. The chorus dancers symbolically represented the feelings of the main characters. A cannon form was used because the cannon form of music has unity and variety built into it. Basically, it is a single theme 
executed at different times. Dancers entered in interval groups. The cannon was repeated again, and in this section, a god from the realm of the dead was reintroduced. The purpose of this section was to show the weakening of Black Jade. Various Chinese symbols were used in the dance including the red material. The red material was used as a symbol of the wedding and of other happy occasions in Chinese customs. The red material was also utilized in the wedding procession to indicate a bridal wedding gown. In Chinese culture, red is a symbol of good luck. Therefore, as in the tradition, the bride wore a red wedding gown.

Capes in the dance were used as in Chinese dance. Chinese garments were worn in ancient times to protect people from the cold. The capes embroidered in gold and silver threads also indicated the high class and wealth of people.

Flowers on the capes, according to Dream of the Red Chamber, represented the names of flowers to portray the twelve maidens' personalities and as symbols for each maiden's life pursuit. The pattern of flowers on the cape indicated each character. In Chinese culture, women were considered inferior to the men. The female's destiny depended on her arranged marriage. Parents selected their daughterin-law in part for a style of personality that was considered to represent a feature of good luck. Thus, the flower used for Black Jade is called "Ling Chih," or "fomes japonica." This flower is a kind of dark, brownish, and hard fungus which is supposed to possess supernatural power. It was chosen to give some indication of Black Jade's destiny. Precious Virtue's flower wás "Yu Lan," or "magnolia," which represents a 
gregarious personality and brings good luck. A kind of purple fern, "Tzu Wei," or "osmunda regalis," was used for Pao-Yu. The flower, "violet," used for Pao-Yu’s character is called "Tzu Wei." The violet color gives an indication of his caring personality.

Movement sequences incorporated modern dance vocabulary and many Chinese dance techniques, such as "Cloud Hand," "Yao Tzu Fan Shen," "Lotus Finger," "Wo Yu," as well as the small walk, "Tie Feet." It also included many Chinese-like poses. During the small walking sequences, the curved torso, arms, and limited head shifts, were used. Sometimes a movement sequence would pause into still and static positions. Occasionally specific Chinese arm gestures such as "Cloud Hand," "Shan Pang," and "Lotus Finger" were used while the movements for the legs and feet used ballet or modern dance technique. Sometimes the dancers moved their torsos in the "Yao Tzu Fan Shen" technique with "Arabesque" legs. Usually, the upper part of the body was limited in movement, while the lower part of the body was active.

Both Chinese and modern dance formations were used in this dance. The first chorus dance used strict Chinese formations. Following the conflict that occurred in the trio, the chorus sections used modern dance formations which were similar but broken in formation.

The use of formations paralleled the style of the music. Chinese music is very even in tempo and continuous with little accent, while Western music reveals a range 
of dynamic qualities and use. This musical score included both styles. The beginning suggested a Chinese style. Following the trio, rhythms and dynamic changes suggested the style of Western music which helped to created the conflict, bringing the dance to a climax. The ending of the music returned to the Chinese style.

Focus is very set in Chinese dance while modern dance focus will vary with the theme. In Chinese dance, focus is utilized by still poses, while modern dance includes focus within the movement sequence and minimizes the use of still poses. Both kinds of focus when held, became a pose and other times, it could be found in the movement sequence. The straight forward focus, a Chinese dance technique, was used to emphasize active aspects. But in the last section of the chorus, a modern dance appearance was utilized by widening the focal point to include every area of the stage.

\section{SUMMARY}

This chapter describes the five dances performed in the concert. Although the descriptions vary, the following elements were adhered to for each dance: the theme, or intention of the choreographer, movement choices, dance elements, music, and movement styles. Depending on the type of dance, and for the purpose of clearly explaining the dances, some categories were emphasized and detailed more than others. 


\section{CHAPTER IV}

\section{CHOREOGRAPHIC ANALYSIS AND RECOMMENDATION FOR FURTHER STUDY}

This project was an attempt to merge apparent contradictory dance stylestraditional Chinese dance and modern dance-into a choreographic work. The preceding chapters describe the movement techniques of Chinese and modern dance, and the choreographic elements used for the purpose of blending the two styles into one form. The purpose of this chapter is to analyze the elements used in the dances and evaluate the result in regard to accomplishing the goal. Did they unify the two forms or not, how did they work and vice versa. The elemental analyses of each dance are listed below.

\section{Enlightenment-solo}

The purpose of the dance was to illustrate the transformation of a human being to the supreme spirit-Nirvana. The choreographer chose a Chinese theme using modern dance technique for movement. However, Chinese dance technique was used for the climax, the transformation section which occurred in the middle of the dance.

The movement in this dance used curved and angular lines. Small and slow curved movements were utilized at the beginning of this dance, as well as even, angular and straight lines for poses. No specific Chinese dance movements were used. 
"S" and square angular movements were applied in the transformation section of the dance. Movements in the figure "S" were used to represent the Chinese fairy theme. The angular, parallel movements and poses were also Oriental interpretations. The end of this dance used poses that were constantly changing for the purpose of building the dynamics. The strong use of dynamics applied through modern dance movement gave the dance a strong, modern appearance.

The colors of the prop and costume in this dance were modern interpretations, but also included Chinese symbolism in the use of material and color. The red and gold colors of the prop symbolized two aspects: red depicting a symbol of good luck, and gold representing a supreme spirituality of traditional Chinese beliefs. The skin color of the unitard symbolized the nature of Buddhism; the major idealogy of Buddhism being that of purity, peace, and unity.

Although the use of the prop as a symbol was drawn from Chinese traditional dance, this subtle difference, as well as the movement in the transformation section, may not have been perceived as a Chinese dance by the audience. Therefore, the dance may not have accomplished the perfect blend of Chinese and modern dance.

\section{Nostalgia-duet}

This dance used a theme based on Taiwanese experience. Although the theme and music were Taiwanese, it was observed that by using only modern dance movement, the audience may not have perceived the blending of the two forms. 
The Martha Graham technique of contraction and release, as well as crawling movements, were modern dance interpretations used in the beginning and middle of the dance. The girl used a primitive movement by jumping and kneeling on the man's back. This is a simple, deep, and angular movement found in modern dance. Lifting the girl or surrounding the man's torso and sinking down to the floor in the duet are Western dance movements. Low squatting positions and still poses were taken from Chinese dance and used to suggest local customs and the earthy young people of a Taiwanese village.

The use of hand gestures, such as raising one hand and stretching, relaxing, and reaching out with the fingers, were modern dance images. However, still poses, with both hands grasping a skirt and one hand holding the windmill, are gestures representative of the local symbols and customs of rural areas in Taiwan. Slow and quick movement between two still poses brought contrast and was used for the purpose of building dynamics in the dance.

Focus in Chinese dance 'projects a long sustaining power after a series of movements or hand gestures. In this dance the use of focus followed the Chinese tradition. Focus was very specific throughout the entire dance, following sequential movements and often projecting directly to the audience, to sustain longer moments.

The theme in the dance was based on Taiwanese customs, the music originated from a Taiwanese folk song, but the movements were not utilized with specific Chinese dance techniques. Although poses in Chinese style were maintained longer 
than usual, and walking in the "tie feet" was used, the movements were basically from modern dance. Hand gestures were used to show an image of infinity, but no symbolic meaning of the Chinese hand gestures was portrayed. Dynamics were built by the differences between slow and quick timing of modern dance movements. The above elements suggested a few Chinese dance techniques, such as an endless quality of movement, but they did not have consistent and specific Chinese styles, or movements, to make it appear as a Chinese dance. Therefore, the dance appeared more modern in style.

\section{Enchanting Celestial-group}

This dance was choreographed and performed to show Chinese traditional dance so the audience could compare the two dance styles used in the program.

Chinese walking and poses with "Lotus Fingers" were used by the five girls at the beginning of this dance. The bodies were moving in the figure of "S" with "Cloud Hand," gradually shifting to different poses using parallel legs, sequential arm movements, and square, angular bent knees. "Yao Tzu Fan Shen" was used prevalently as a transition for this part of the dance. Jumping in the air with the torso in "S" movements were Oriental interpretations.

A solo was performed in the second part of the dance. The curved torso, arms and feet while turning in the air or on the ground were applied. The use of movement in the solo was similar to the first part of the dance. However, the timing 
of movements was different using intensive walking, quickly changing poses and directions.

The last part of the dance presented various images of Buddha figures and hand gestures. The poses used curved torsos, moving in the figure of the " $\mathrm{S}$ " movements, flexed feet, and Buddha hand gestures. Back bends and splits were used in the dance as acrobatics. The movements, "She Yen," "Chin Chi $\mathrm{Tu} \mathrm{Li"} \mathrm{were} \mathrm{also}$ used. They are specific Chinese dance movements which mean standing on one leg while extending the other.

Poses in this dance presented strong Chinese visual images. Various methods were employed as follows: stop actions during the intensive walking, shifting the torso and alternating with poses, and poses followed by continual actions. "Liang Hsiang," a sudden stop action of a moving object, and described as a Chinese performance technique, was used as focus in this dance. "Liang Hsiang" was directly projected by a small shifting of the body, a suspended pose, or a spiral turning of the torso. Such methods are primarily used in Chinese dance and not in modern dance, offering clear indications of the contrast between the two styles.

A skin colored unitard, the red silk strings, and green silk baggy pants of the costumes were used to depict a light Chinese quality in this dance. The original color of red and green costumes expressed purity. A piece of red string represented the spirits in the Chinese fairy dance. The baggy pants are Chinese traditional costumes used in ancient times. The slow and continuous tempo of the music, and the drawn- 
out tones are typical in the Chinese style of music.

This dance clearly represented Chinese traditional dance. The Chinese forms expressed very strong movement images supplemented by the addition of Chinese costumes, headdresses and music.

$\underline{\text { Horizon-trio }}$

In this particular dance, the only form and style of movement was modern dance. The Chinese connection in this piece was the thematic idea of wanting to break away from Chinese tradition. The dance was selected to show modern dance choreography in order to allow the audience to see the contrast between modern and Chinese styles of dance.

Though stylized, the modern dance movements, such as the walk, the run, and the fall, were performed in a simple form. The body, shifting of the torso, leg extensions, and head movements were used in vertical and curved lines.

Symbolic images were shown by using many hand gestures to express the thematic ideas. Such gestures included the hand covering one side of the face, and the arms reaching outward. Other symbolic images could be found in various group formations through body designs, special forms, and weight usage. For example: the duet used three vertical lines simultaneously with curved lines, two straight lines overlapping each other, the body hanging on another body, and a contrasting of classical lines with broken lines. One of the differences between Chinese and modern dance is that the images in Chinese dance are stilted, whereas in modern dance, the 
images have a continual flow. Such continual flow was used primarily in this dance.

Modern dance was dominant in this piece because of the Western music and movement selection. Irregular timing of movements and directions created the dynamics in the dance. Although the dance used a Chinese theme, the dance was perceived by the audience as a modern dance piece.

\section{Dream of the Red Chamber-group}

The blending of the two dance styles, modern dance and Chinese traditional dance, into one choreographic piece was the choreographer's intention. In this dance, the choreographer used both styles, techniques and forms, as well as theatrical elements which included props, costumes, make-up, and headdresses. The theme, although it followed a Chinese story, could also be interpreted in both dance styles. The music, as mentioned in Chapter III, used both Eastern and Western musical forms.

Symbolic meanings were generally applied with both Chinese and modern dance styles. Chinese symbols were depicted in the prop, the flower capes, and specific hand gestures used in the dance. The prop, a red material, was used to symbolize a wedding and other happy occasions. The flower capes depicted the twelve maidens' personalities and a symbol for their fortunes. The hand gestures represented in the first chorus were used to suggest unity. The last chorus utilized modern dance movements as a symbol of anxiety. 
The costumes depicted both styles of "Chinese and modern dance, such as flowered capes, unitards, and headdresses. The dancers wore Chinese-like headdresses, which were a modification of traditional Chinese headdresses. The headdresses were modified by adopting the feature of a Chinese traditional headdress and simplified to give a modern approach. The women's hair was tied in a bun either on the back, the top, or by the side of the head and adorned with Chinese-like headdresses. The dancers' headdresses used flowers instead of the traditional Chinese complicated decorations, such as jewelry. The flowered capes represented personal characters in the dance, and when the dancers took off their capes the unitards gave a modern appearance. Make-up was no different from that used by modern dance.

Movement in this dance was selected from Chinese and modern dance technique. Chinese movement had little change in interpretation, and modern dance movement was used often to show the individual style of the choreographer. Specific movements such as "Yao Tzu Fan Shen" and "Wo Yu" from Chinese dance and curved, angular movements from modern dance were used to blend the two styles. The difference between the origin, the design, and the size of movement became qualities which indicated the inward, balanced, and controlled movement of Chinese dance and the outward, angular, and expansive movement of modern dance.

The movement of the three main characters at the beginning of the dance utilized both Chinese and modern dance. Movement for Black Jade, Precious Virtue, and Pao-Yu, applied Chinese dance techniques representing "Lotus Fingers," "Yao 
Tzu Fan Shen," and "Wo Yu." Western dance movements included "Arabesque," "À La Seconde Développé" and "Relevé."

A contrast between the two styles was shown by alternations of Chinese and modern dance movement. These alternations consisted of a body tilt turning with "À La Seconde Développé" to "Yao Tzu Fan Shen," a twisting torso turning to "Wo Yu," and a twirling head to "Yao Tzu Fan Shen" with "Lotus Fingers." This blending of the two styles of movement (modern dance with a few Chinese dance techniques) may not have been obvious to the audience.

The movement in the first chorus was performed in harmony. The specific Chinese dance movements used were "Yao Tzu Fan Shen," "Cloud Hand," and "Lotus Fingers." Modern dance movement included curved and soft lines to give a Chineselike appearance. Movement in the trio was outward, angular, and free. The timing of the movement was short and quick, making the modern images stronger than the Chinese images. However, the movement of Black Jade occasionally revealed Chinese dance technique by the use of inward, weak, and small movement, as well as slow timing. In the wedding section, curved lines were used instead of specific Chinese dance technique. In the last section of the group dance, imbalance and disharmony were shown by quick and short individual modern dance movements.

The major difference between the two styles can be found in the use of the dancers' formations. In Chinese formations, circles, diagonals, and parallel lines are always even, square, and balanced with the space. In the first chorus, where the 
women are introduced, these formations were used. At the same time, modern dance movement was used by the male soloist offering a contrast of the two styles. The trio used the horizontal line common in Chinese dance, and broken formations used in modern dance. Chinese-like designs and body shapes (poses) were used. The duet of Black Jade and Pao-Yu used modern dance formations. The wedding of precious Virtue and Pao-Yu used Chinese square dance formations. The modern dance formations in the last group dance were broken into isolation. Formations clearly served to contrast Chinese and modern dance styles.

In conclusion, Chinese and modern dance styles were incorporated in this dance. Various symbols were both Chinese and modern dance interpretations. The flower capes and headdresses of the costumes were adapted from traditional Chinese costumes and simplified with a modern approach. The unitards are a frequent modern dance costume. Movement, as well as the musical form, included botin Eastern and Western styles. Movement was alternated between specific Chinese and modern dance techniques. Formations became very clear when the group and individual formations were used in the dance. All of the dance elements mentioned in Chapter II incorporated both Chinese and modern dance styles in this particular choreography.

\section{SUMMARY}

The purpose of this chapter was to analyze and assess the effectiveness of the 
choreographer's intention to use the two styles of dance: Chinese and modern dance.

A Chinese theme and Chinese music were used in the first solo dance, Enlightenment. Chinese "S" techniques and square, parallel angular designs in the body were used. However, the blending of modern dance and Chinese dance movement gave a strong modern dance appearance and therefore was not obviously revealed as a Chinese dance. As in the first solo dance, Enlightenment, and the second duet, Nostalgia, Taiwanese themes and music were utilized, but movement and costumes were very modern in interpretation. Again, this dance did not reflect a blend of dance styles. In comparison, the third Chinese dance, Enchanting Celestial, clearly utilized Chinese headdresses and costumes. Movement was drawn from the Chinese spiritual dance style. To contrast Chinese dance, the fourth dance, $\underline{\text { Horizon, }}$ was a purely modern piece. The intention of the choreographer was to show the breaking of Chinese traditions. All of the interpretations were Westernized. The use of a Chinese theme could also be applied as a modern interpretation, and therefore, presented a strong modern dance style, in contrast to Enchanting Celestial. However, in the last dance, Dream of the Red Chamber, the purpose was to blend the two styles of dance. Most of the movement was equally blended in the two styles, drawing from specific movements of Chinese dance, and the freer movement of modern dance. The introduction of the main characters was modern, while the introduction of the chorus was Chinese. From the climax to the end of the dance was a blend of both styles. Movement style, when blended, projected a modern interpretation. Chinese 
costumes and headdresses were simplified to also suggest a modern aspect. The most obvious elements seen from the two different styles were: movement formations, stilted versus flowing designs, focus and performance techniques, and movement selection. In addition, the formations obviously served as the main distinction between the two styles in the dance. Various choreographic dances were used to help effect and enhance the objective of blending the styles of Chinese and modern dance.

\section{SUMMARY AND RECOMMENDATIONS}

This project was an attempt to merge and perform apparently contradictory dance styles-classical Chinese dance and Western modern dance. The solution was to create dances in which a Western sense of movement embodied Chinese philosophical values, resulting in a new movement style. Since modern dance incorporates various styles of movement, it was difficult at times for the audience to differentiate between the two movement styles or perceive the movement as a new movement style. In retrospect, the following suggestions are given concerning this project with recommendations for future experiments:

1) Change the order of the program and start with the Chinese traditional dance, Enchanting Celestial, contrasted with the pure modern dance, Horizon, followed by the modern duet, Nostalgia and solo, Enlightenment, and end with the Dream of the Red Chamber. This would help the audience see the contrast of the two pure dance styles and then help clarify the blending found 
in the last dance.

2) Consider exploring further with Chinese make-up and masks.

3) Emphasize more Chinese dance movement and performance techniques.

4) In Nostalgia and Enlightenment, use material objects such as props, costumes, and sets to help project Chinese images, since Chinese themes and concepts are very esoteric. Chorus members moving the props or sets, common in Chinese opera, could be explored further in the last dance.

5) Choreograph movements that are contained separately, since both forms are highly stylized, and alternate the sequences. Blending both at the same time often created a modern dance look.

6) Utilize more Chinese dance formations, since formations seem to be one of the strongest elements differentiating the two styles.

7) Choreograph dances separating the dance elements identified in Chapter II. For example, choreograph two dances both with the same theme, one danced in traditional Chinese dance style and the other in modern dance style. Then experiment by exchanging the music, movement, other dance elements and theatrical devices. There are many combinations possibie.

8) Explore other cultures and movement styles for the purpose of blending with modern dance styles. 


\section{BIBLIOGRAPHY}

1) Chao Li-Lian, Hu Heng, Liang Tsai-Ping, Lo Fang, Weng Te-chen. Chinese Art. Trans. Harold L.K. Siu. Taipei: Youth Culture Enterprises, 1985.

2) Juan Chang-Jui. The World of Dignity. Taipei: Wen Kai Enterprises, 1982.

3) Liang Hsiao-Chuan. SHOU-YEN-SHEN-FA-PU: Movement Method for the Females Roles of the Chinese Theatre. Ed. Wang, Chi-Mei. Taipei, Taiwan, Republic of China, 1983.

4) Lynne Ann Bolm and L. Tarin Chaplin. The Intimate Act of Choreography. Pittsburgh: Univesity of Pittsburgh press, 1982.

5) Tsao Hsueh-Chin. Dream of the Red Chamber. Trans. Wang Chi-Chen. Singapore: Graham Brash, 1983.

6) Webster's New World Dictionary, Second College Edition. Ed. David B. Guralnik. U.S.A.: William Collins \& World Publishing Co., Inc. 1976. 
APPENDIX

Concert Programs and Pictures 

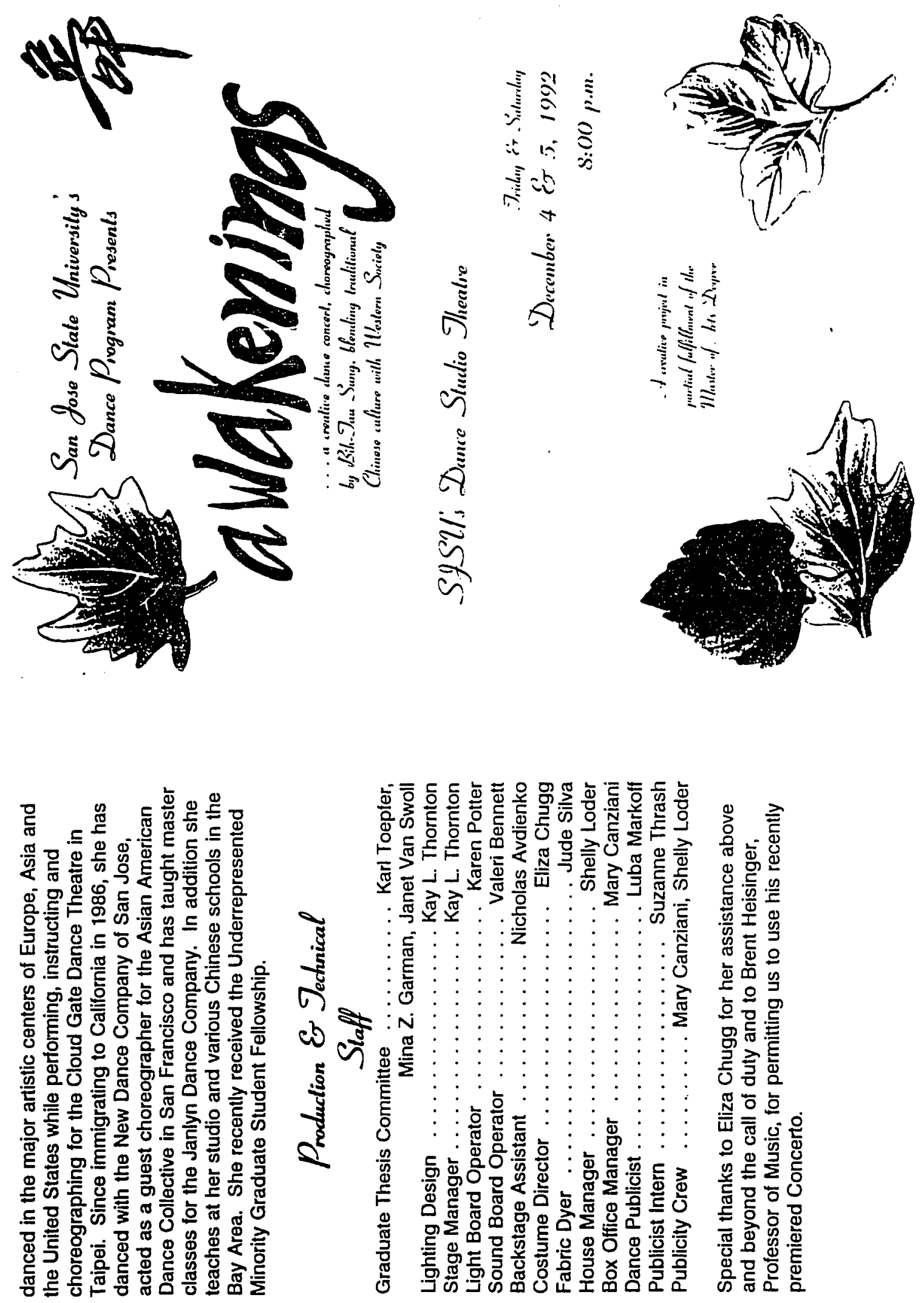

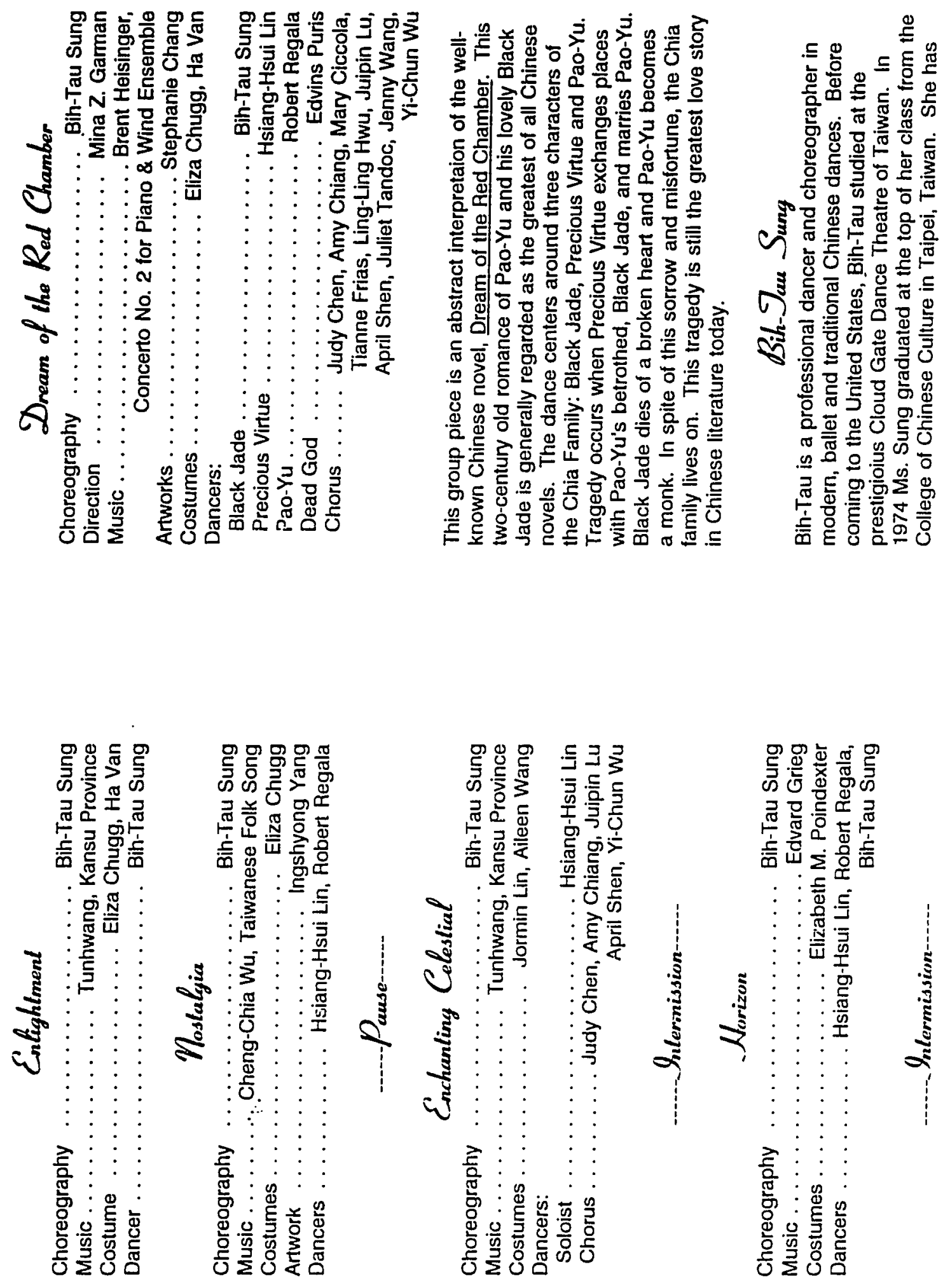


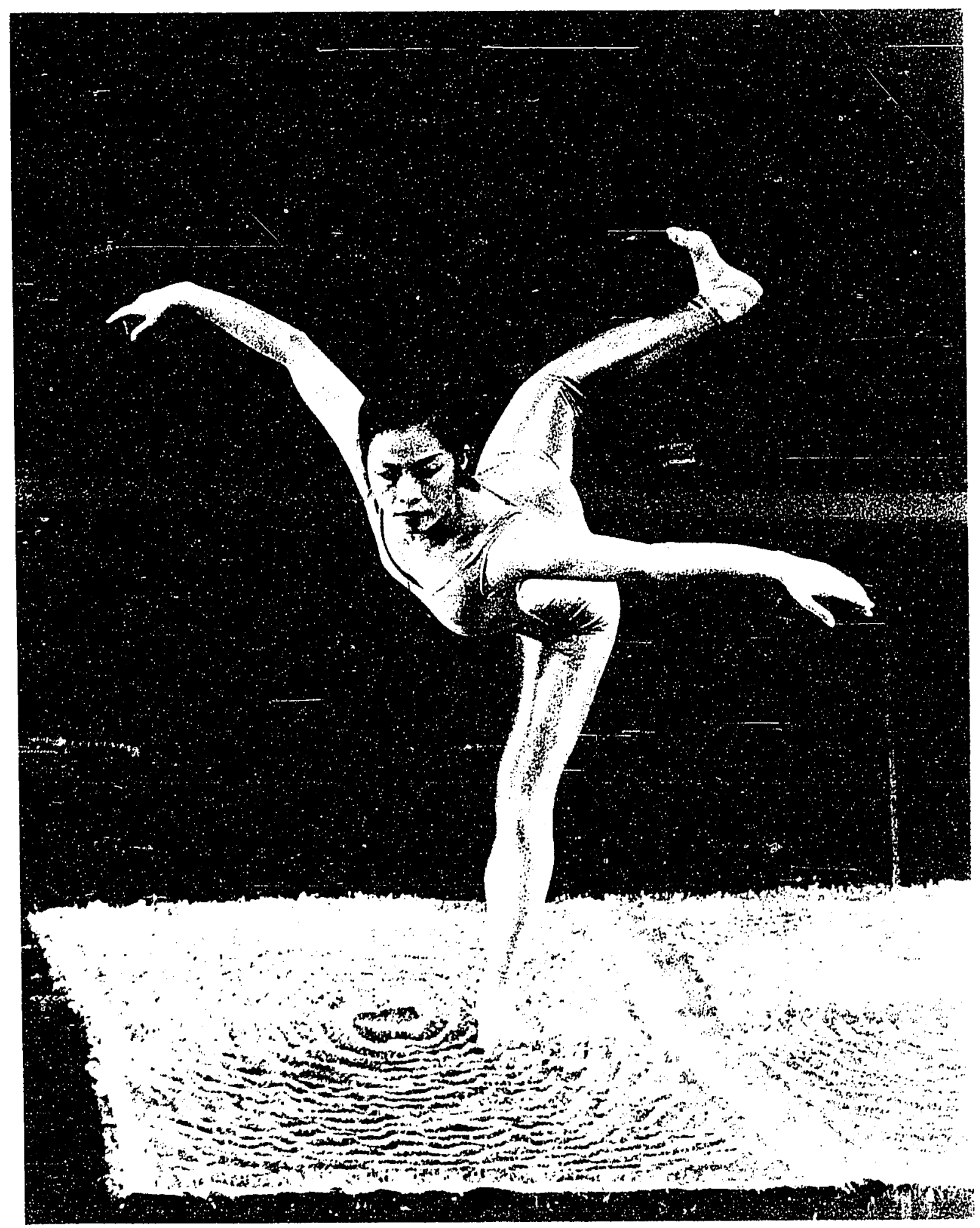

Figure: Enlightenment 


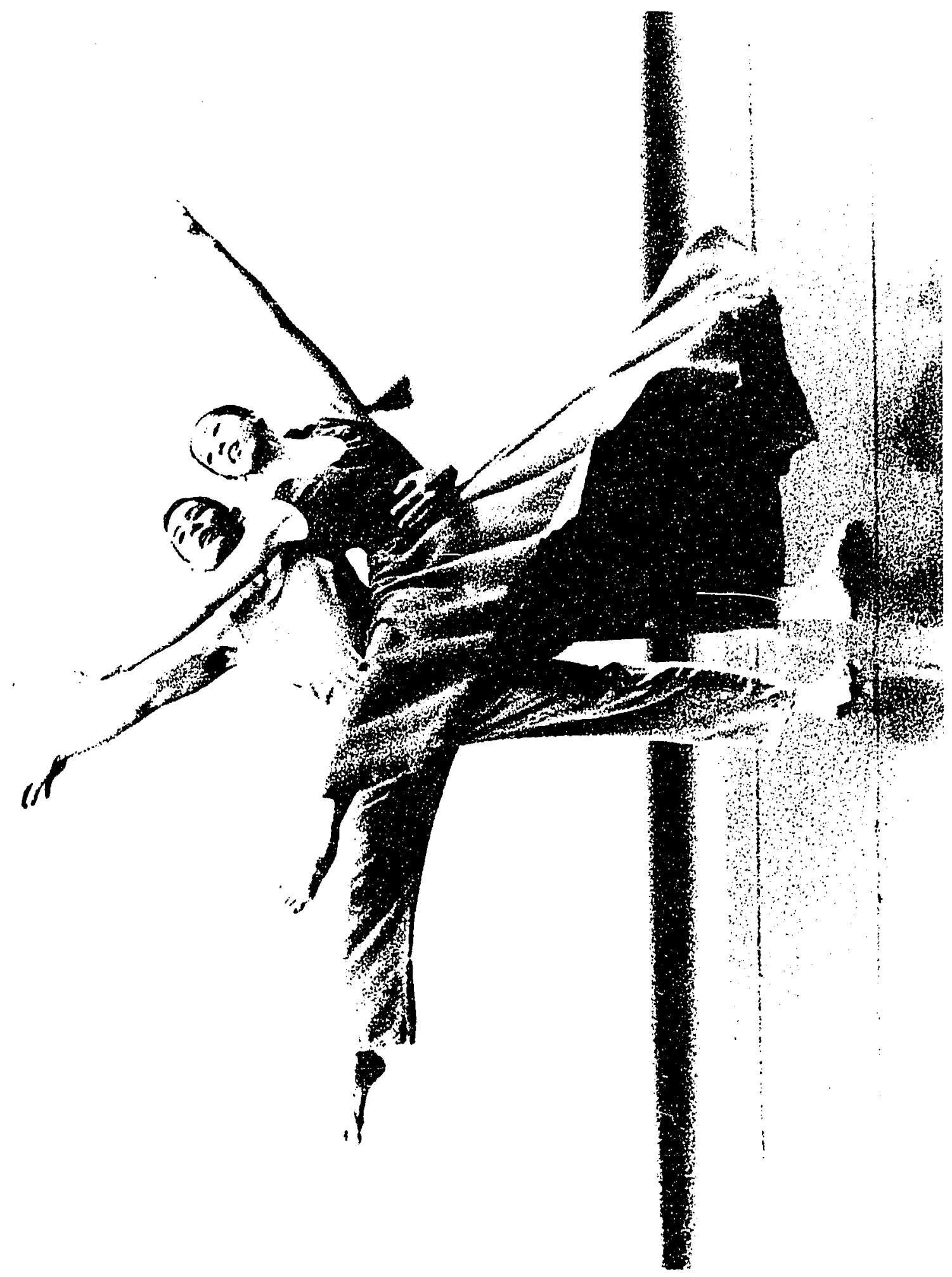

Figure: Nostalgia 


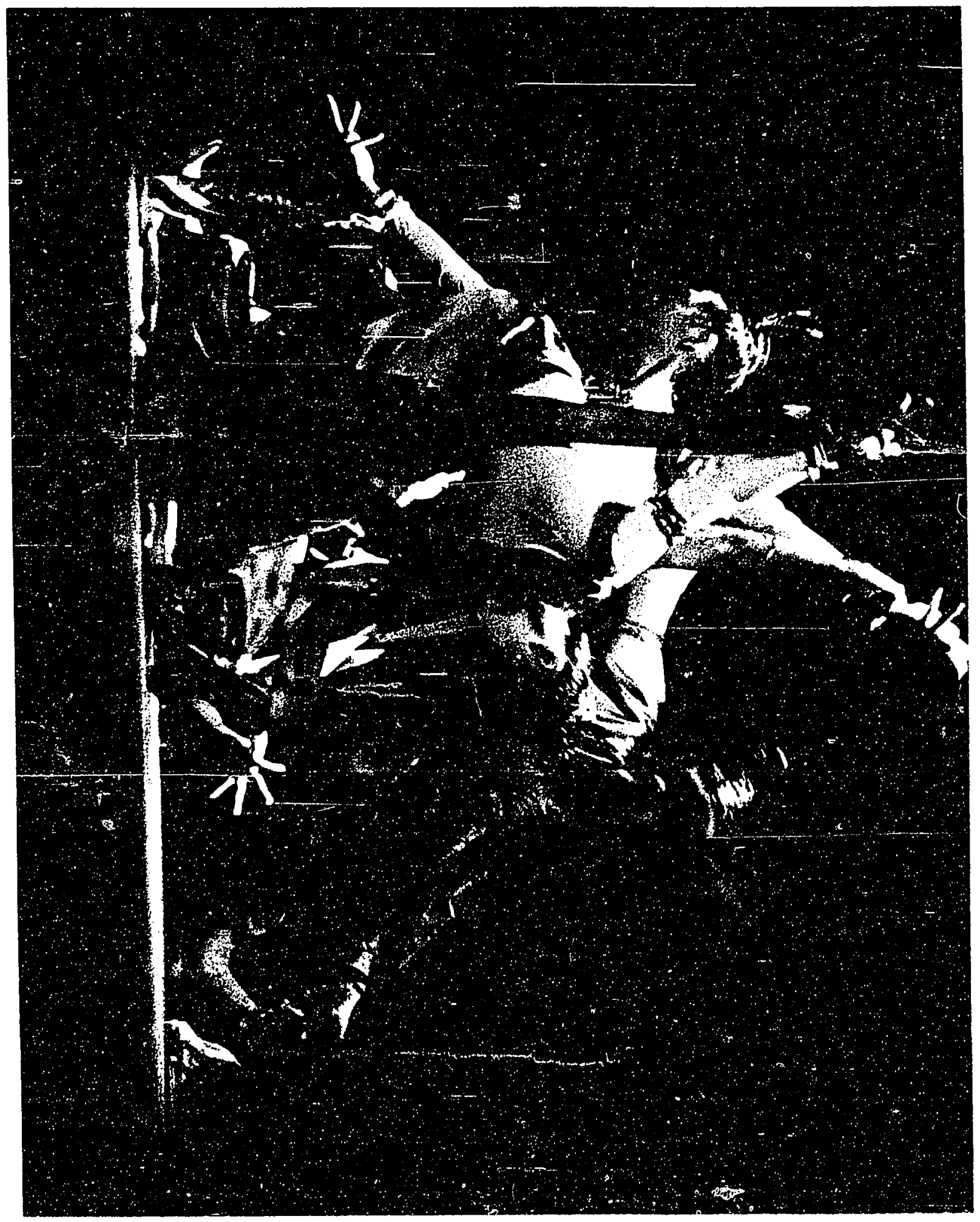

Figure: Enchanting Celestial 


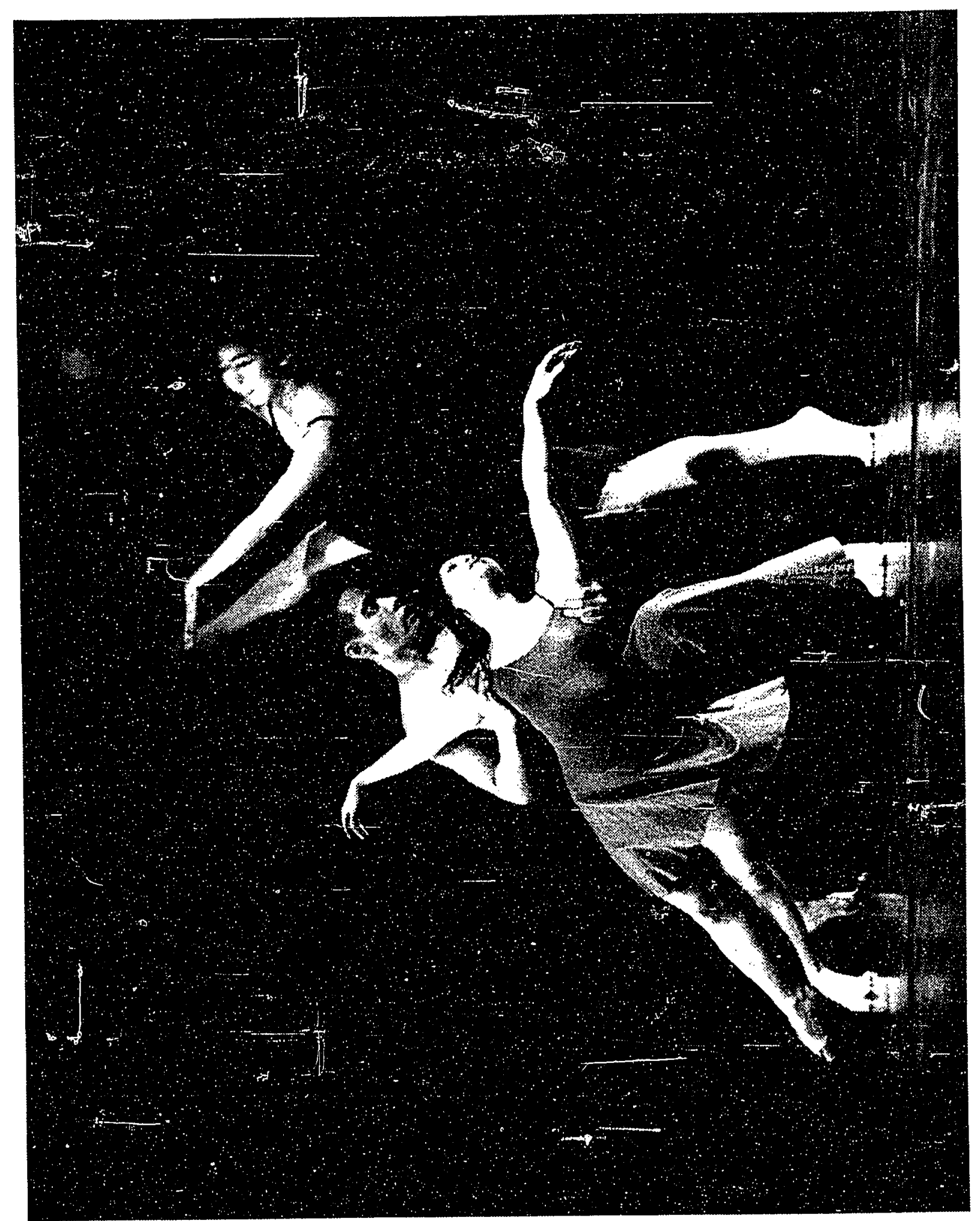

Figure: Horizon 


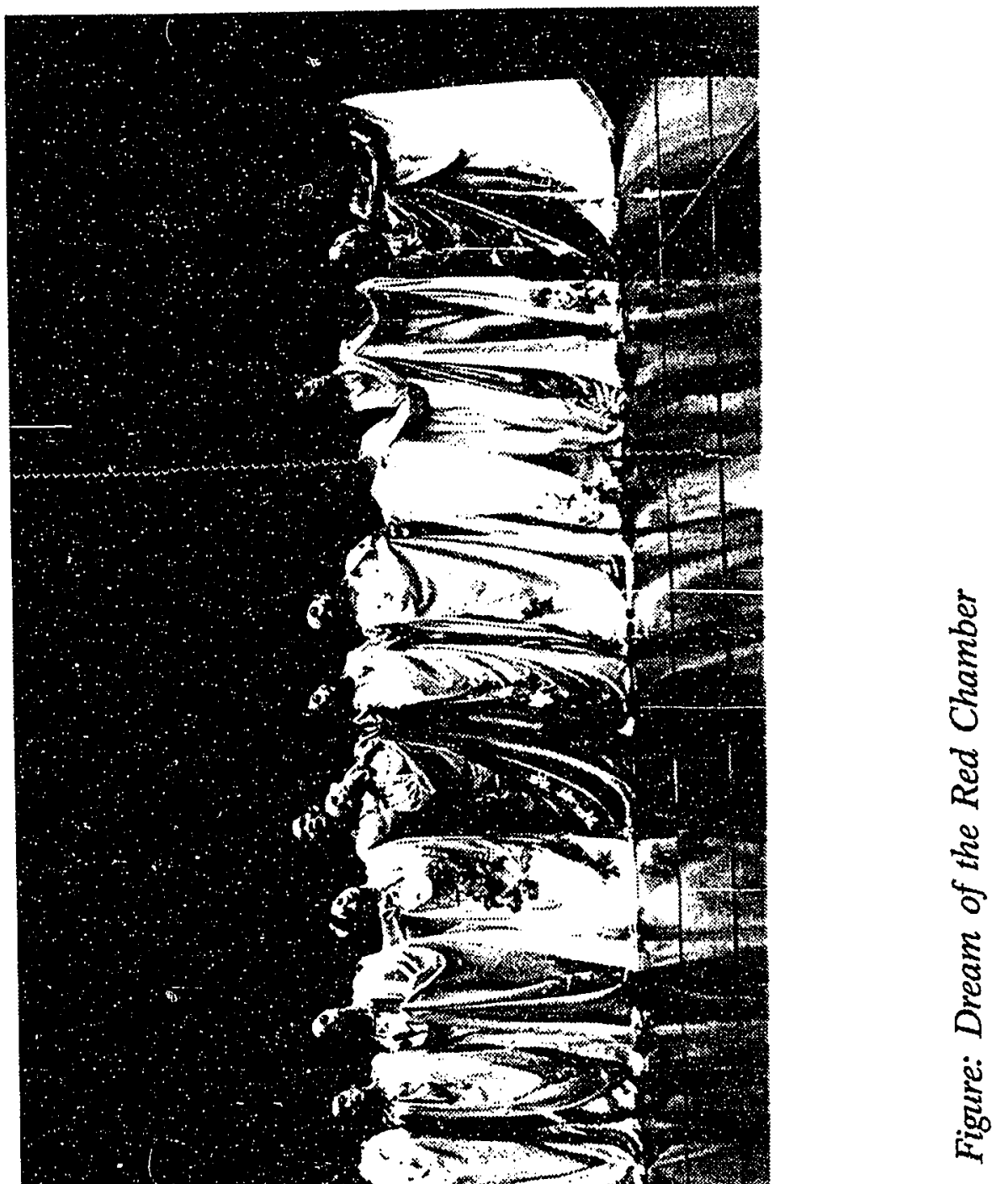

踏 